\title{
A Functional Analysis of the e-WAT with Specific Focus on the Mobile Version: Towards a Model for Improvement
}

\author{
André du Plessis, Department of Afrikaans and Dutch, \\ Stellenbosch University, Stellenbosch, South Africa \\ (ahduplessis@iafrica.com/15612538@sun.ac.za)
}

\begin{abstract}
Lexicography's identity crisis leads to a shift towards electronic lexicographic tools. The rise of mobile phone and smartphone usage in South Africa also creates the opportunity for lexicographers to exploit a new market. This article looks at the current state of Afrikaans mobile dictionaries as an opportunity to delve into this market. The electronic WAT is analysed by primarily applying the function theory to show where user needs must be addressed. This leads to a model for improvement of this and possibly all other mobile dictionaries in South Africa.
\end{abstract}

Keywords: AFRIKAANS, APPLICATIONS, E-DICTIONARIES, E-LEXICOGRAPHY, ELECTRONIC LEXICOGRAPHY, FUNCTION THEORY, MOBILE DICTIONARY, MOBILE PHONE, LEXICOGRAPHIC TOOLS, SOUTH AFRICAN LEXICOGRAPHY, WAT

Opsomming: 'n Funksionele analise van die e-WAT met spesifieke fokus op die selfoonweergawe: 'n grondslagmodel vir verbetering. Leksikografie se identiteitskrisis lei tot 'n verskuiwing na elektroniese leksikografiese gereedskap. Die groeiende tendens van sel- en slimfone in Suid-Afrika skep ook die geleentheid vir leksikograwe om 'n nuwe mark te ontgin. Hierdie artikel kyk na die onbevredigende toestand van Afrikaanse selfoonwoordeboeke as grondslag vir verdere ondersoek in hierdie sfeer. Die elektroniese WAT word ondersoek deur die funksieteorie toe te pas, om veral aan te dui waar die gebruiker se behoeftes aangespreek moet word. Dit lei tot ' $n$ model vir die verbetering van hierdie en moontlik alle ander selfoonwoordeboeke in Suid-Afrika.

Sleutelwoorde: AFRIKAANS, E-LEKSIKOGRAFIE, ELEKTRONIESE LEKSIKOGRAFIE, EWOORDEBOEKE, FUNKSIETEORIE, LEKSIKOGRAFIESE INSTRUMENTE, SELFOON, SELFOONWOORDEBOEK, SUID-AFRIKAANSE LEKSIKOGRAFIE, TOEPASSINGS, WAT

* This article was presented as a paper at the Nineteenth Annual International Conference of the African Association for Lexicography (AFRILEX), which was hosted by the Research Unit for Language and Literature in the SA Context, North-West University, Potchefstroom Campus, Potchefstroom, South Africa, 1-3 July 2014. It forms part of a master's thesis and is ongoing research. 


\section{Introduction}

Lexicography is at a crossroads. With the advances in technology and the market shift towards electronic tools, the need for digital lexicographic tools is growing (Anderson and Nielsen 2009: 360-362). This means that the areas of theoretical and practical lexicography overlap in the sphere of electronic lexicography. This article will investigate the South African, and particularly the Afrikaans, lack of quality electronic lexicographic tools. The focus will specifically be on mobile dictionaries. A functional analysis of the mobile and online versions of the WAT is undertaken. This analysis creates the opportunity to develop guidelines or recommendations to improve mobile lexicographic tools in South Africa and even abroad.

Extensive international research has been done on e-lexicography and it seems that there is an evident shift towards electronic dictionaries from a theoretical and publishing perspective (cf. De Schryver 2003; Fuertes-Olivera 2009; Heid 2011; Tarp 2012; Lew 2012; Oshima 2013, Smith 2013). South Africa is slowly catching up (cf. Bothma 2011, Prinsloo, et al. 2012, Gouws 2011), but more needs to be done. More projects like SeLA, i.e. the DAAD-funded "Scientific e-Lexicography for Africa", an international collaboration that has yielded some very good research on (South) African lexicography, are needed to kick start the process. This study aims to add to this research output. It must also be added that the goal here is not to criticise good dictionary data, but rather the vessel that the data is presented in.

Please note, for the purpose of this article, the term mobile dictionary does not include other electronic devices such as palmtop dictionaries, even though they are mobile electronic tools (See Tono 2009).

\section{Research problem and motivation}

This study has a dual focus. First, different theoretical principles are studied to determine the theoretical scope to use for an analysis of this nature. This will be briefly explained later on. The physical and technological attributes of mobile phones are taken into consideration as well.

Secondly, the lack of research on Afrikaans mobile dictionaries, as well as the inadequate nature of the current selection of mobile dictionaries available creates the opportunity for further investigation. The nature of one Afrikaans mobile dictionary will be studied. This is important because it is a linguistic resource that can empower many Afrikaans speakers, as well as permeate into other language and culture groups. Thus, the WAT forms the core of this analysis, and is chosen because of its prominence, huge database and availability (as there are no other suitable dictionaries available).

Furthermore, the advances in technology and the fact that there is a global commercial and research shift towards electronic tools, adds motivation to do a study of this nature. Lexicography's current identity crisis, i.e. the split between 
printed and digital media, also fuels this fire (Andersen and Nielsen 2012: 360). Tarp (2009: 17) gives three main reasons for this identity crisis:

1. "The theoretical efforts carried out during the last decades and the growing schism between the most advanced theories and the majority of dictionaries produced today;

2. The development of the new computer and information technologies and the present transition from printed to electronic dictionaries;

3. The advent of the so-called information and knowledge society and the growing need for quick and easy access to information."

These reasons essentially act as motivation to delve into electronic lexicographic research. From this perspective it is important that modern and future users be addressed, especially in an era where the mobile phone plays such an immense role in day-to-day activities. This medium cannot be ignored as a possible solution for the need for fast, effective and specialised lexicographic tools.

\section{The South African e-lexicography situation}

South Africa is a multicultural country with 11 official languages. With the establishment of the National Lexicographic Units (NLU) between 1997 and 2001, a greater emphasis has been placed on language development and dictionary design (Prinsloo 2012: 121). As Prinsloo (2012: 121) indicates, it is an expensive and impractical process to treat every language the same when concerning lexicographic resources. This is reflected in the online dictionaries available to the South African user. Only Afrikaans and English have proper edictionaries, whereas Xhosa, Zulu and Sepedi have some form of online dictionaries (Prinsloo 2012: 120-121). It seems that it is not profitable or marketable to design e-dictionaries for the other languages. There are however, current developments in the Afrikaans and Bantu language electronic sphere that must also be taken into account (See Prinsloo 2012).

According to Peyper (2013) there are more mobile phone users than computer users in South Africa. Buys and Malebo (2004: 67-68) indicate that since the inception of cellular communication in South Africa in 1994, mobile phone users increased from 0 to 18 million users in just 10 years. The latest general survey done by Statistics SA (2013) also shows that more than 15000 households have at least one cellphone owned by the head of the family. That might seem like a small number but it must be noted that other members of the family were not included and that not all households were/can be surveyed. It can thus be argued that if these factors are taken into consideration, the given statistic will certainly increase and would be more akin to that of Buys and Malebo's (2004) research. There is also an already steady foundation of smartphone users in South Africa. In 2011 15\% of the population used smartphones and 32\% in 2012 (Our mobile planet 2013). The latest statistics show that $40 \%$ of 
the population are now smartphone users (Our mobile planet 2013). This is an important statistic, as it shows South Africans' tendency to explore faster and better mobile tools.

When the situation above is scrutinised one logical conclusion is that mobile phone usage in South Africa is likely to grow even faster in the near future. Hence it is imperative that this market be fully exploited and researched from a lexicographic point of view (See for example Winestock and Jeong 2014 for a look at the dictionary app market's growth). Languages that are struggling to adapt to the online sphere or that have a small dictionary market can use mobile dictionaries to start satisfying their users. The NLUs that struggle to find publishers could shift their focus to reaching a new generation of users, whilst instilling a dictionary culture in South Africa and ultimately develop a wide range of users' lexicographic skills in new innovative ways (Prinsloo 2012: 122).

When placing Afrikaans under the microscope, it becomes clear that no fully functional Afrikaans mobile dictionary currently exists. The most Afrikaans dictionaries are mere electronic versions of the printed format. This is not a sustainable model for the future. This also means that these dictionaries were not designed as electronic tools. This has the added implication that the user does not get a usable tool to satisfy his or her lexicographic needs. One such dictionary is unfortunately the e-WAT. However, before this dictionary can be analysed, the necessary theoretical framework must be set out. The following section will give a brief overview of the key aspects used for the analysis.

\section{Theoretical analysis of Function theory}

The most lexicographic theories are aimed at printed dictionaries, which mean that there is currently a lack of theories for the electronic sphere (Tarp 2009: 2324). This leads theoretical and practical lexicographers to adapt existing theories for this sphere. One theory that can be adapted is Bergenholtz and Tarp's (2003) function theory as it is fundamentally designed to not be medium specific. This theory focuses on the user and his/her needs. There are four main function types: text reception, text production, translation and cognitive functions (Tarp 2000). The presumption is thus that by using the function theory as part of the theoretical lexicographic approach and applying it on the electronic sphere of mobile dictionaries as part of the practical approach, gaps in the mobile dictionary sphere can be uncovered.

De Schryver (2003: 147) poses an important question that forms the cornerstone of this analysis: "Who accesses what where?" It is essential that the lexicographer take the user of any dictionary into account, as well as where and how the dictionary will be accessed and used. Therefore, a typology of user-needs and usage situations must be drawn up. This leads to the composition of user-profiles, i.e. a specific set of criteria selected or applied to a specific target-user.

The function theory demands that the users' usage situations be typified. There are two main usage situations, namely communicative and knowledge- 
orientated (or cognitive) situations. Communicative situations encompass any problems a user experiences with communication, whereas knowledge-orientated situations have to do with situations where the user requires extra information on a specific matter (Tarp 2000: 195).

It is important to note that these functions are always linked to a specific user in a specific context. No two users are alike with regards to their needs, but there are overlapping similarities between users and user-groups which make it possible for dictionary designers to adapt to the majority of needs. Essentially everything in a dictionary is based on functions therefore the user and usage situations form the core of this theory.

\section{The Function theory and mobile phones}

The electronic medium provides lexicographers with many new and exciting challenges and opportunities. One such opportunity is the fact that a dynamic interaction between user and dictionary can be created. With accessible and manipulable data at the touch of a button, comes new lexicographic challenges all attached to user-needs. As Haas (Bergenholtz and Bothma 2011: 55) states: "the perfect dictionary is one in which you find the thing you are looking for preferably in the first place you look."

This needs to be kept in mind when working with mobile dictionaries. Users want the correct information promptly and easily. They want to solve problems with the least amount of work. Therefore, mobile dictionaries need to be portable and practical problem-solving tools. Bergenholtz and Bothma (2011: 61-62) also link this to "extra lexicographic tool situations":

- Interpreting situations: a user needs help to define or understand signs, e.g. traffic signs, so that he/she can interpret it correctly and follow instructions if need be.

- Operational situations: the user needs help with cognitive or physical operations/processes. The user usually needs guidelines or help with instructions to complete the task.

- Mediating situations: the user needs a portal where he/she can communicate with the lexicographer/developer to log complaints/queries/comments. This is mutually beneficial as it can improve the dictionary on a continuous basis.

Mobile phones, especially smartphones, make these situations tangible. Harnessing the capabilities of the modern smartphone allows dictionary designers to include elements such as quick-links, multimedia, ostensive articles, external sites and effortless communication. This will in turn address the above-mentioned situations. For example, if a user does not understand a certain sign, he/she could be linked to an external site or a multidimensional middle-text with advanced search functions, lists, diagrams, etc. There are still limitations 
with cellphones, but lexicographers are not currently exploiting the sophisticated tool that almost every modern user has in his/her possession. It is here that this study aims to make an impact.

\section{The WAT}

The printed version of the WAT is generally a good dictionary. The e-WAT has potential, but there are some glaring faults that impede effective functional dictionary use.

The WAT is a synchronic and comprehensive multipart dictionary with some diachronic elements. The CD-ROM version was first published in 2003 and the online and mobile versions in 2006, although these versions are in fact mere electronic copies of the printed version. The WAT includes the standard variety and some prominent varieties of Afrikaans. It assumes that its target users are all mother-tongue speakers of Afrikaans, but focuses predominantly on the range between senior high school pupils and academics, in other words more advanced users of Afrikaans (Elektroniese WAT 2013). This in itself is a contradiction, as cultural, cognitive and usage-situation factors determine the skill and ability of users, in other words the data presented cannot and does not suffice for all target-users if these said factors are taken into account. Furthermore, a comprehensive dictionary does not have a main function, but the WAT encompasses the functions of text reception, text production and knowledgeorientated functions. The problem with this is the application and manipulation of these functions. A user does not have the choice to select which function they would like to access. This will be explained in detail later on.

Having a good printed version should ideally provide a platform for creating an even better electronic dictionary, as a vast amount of workable data is electronically available, as well as a solid foundation of lexicographic principles that are in place. Unfortunately this ideal does not exist yet, which means that the e-WAT is only a more practical and usable tool than the printed version merely due to users having all the parts in one environment with quick access to lemmas through a search function.

\section{Technical Analysis of the e-WAT}

Before the mobile version can be dissected, a quick look at the online version is needed. These two versions are very similar and the e-WAT stems from the online one, so analysing the online one allows for a more comprehensive analysis all-round. This analysis, as mentioned, is done from a functional perspective, i.e. taking the user's experience with the dictionary into consideration. This also means that effectiveness and usability is ultimately tested.

Figure 1 shows the online version's homepage and basic search function. There are also links to the mobile version, advanced searches, outer-texts and information about the WAT. Figure 1.1 shows the online WAT's advanced 
search option. This is an acceptable search mechanism but still needs refinement, especially concerning fuzzy logic and user guidance or error. There is also no way to sign out of the dictionary or to start a new fresh search. Moreover, there is no way to go back to previous searches; unless the web browser's back button is used which then requires the user to refresh the web browser. It would be sensible to have a link that allows users to see their previous searches or have a back button available in the dictionary itself. These might be small things, but they cause frustration and needs to be streamlined to enhance the dictionary's effectiveness.

\section{Absa, vir Afrikaans wat leef}

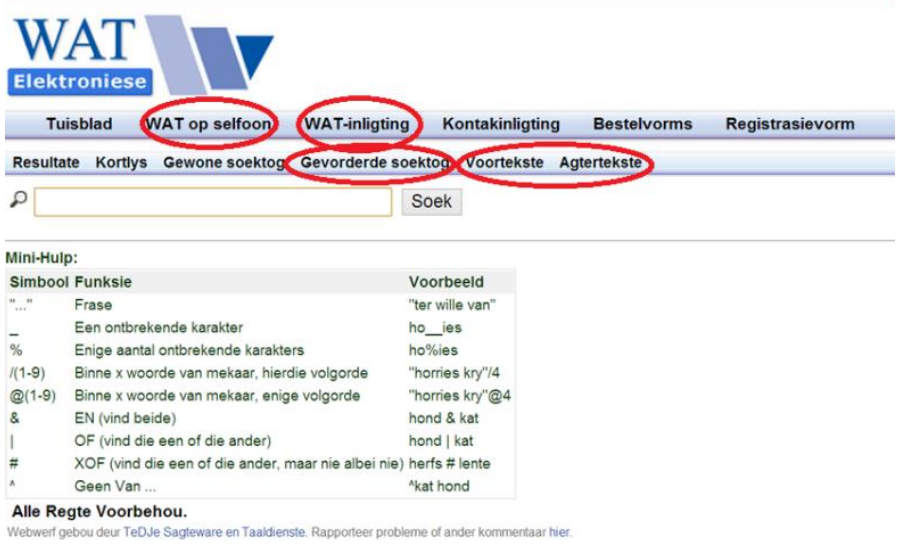

Figure 1: The online WAT

\section{Absa, vir Afrikaans wat leef}

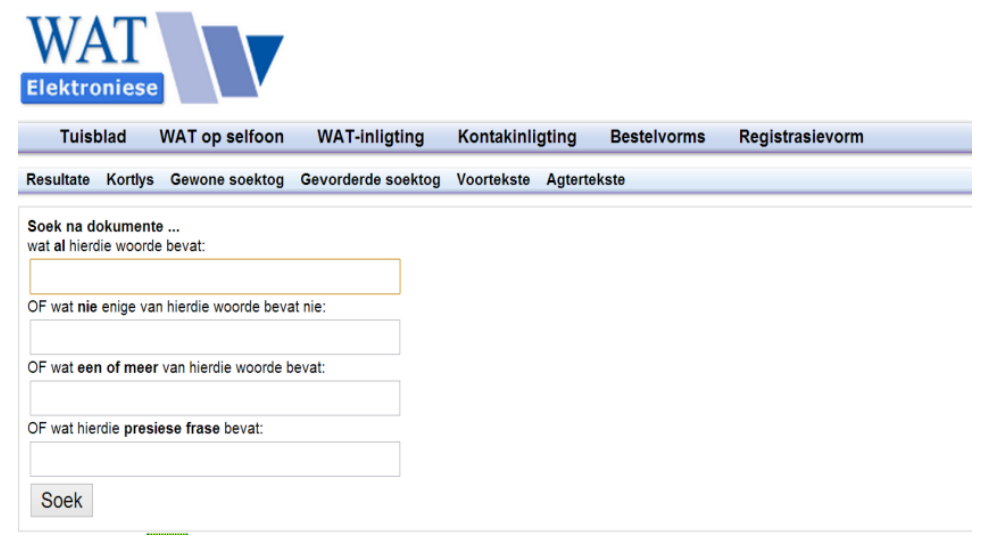

Figure 1.1: Advanced search options 
The dictionary seems static and limited (much like a printed dictionary), apart from the reasonably usable search function and the accessibility of all the parts. Some elements make it rather frustrating to use or serve no real lexicographic purpose and should be reconsidered. Figure 1.2 and figure 1.3 show elements that need to be addressed to improve functionality and usability:

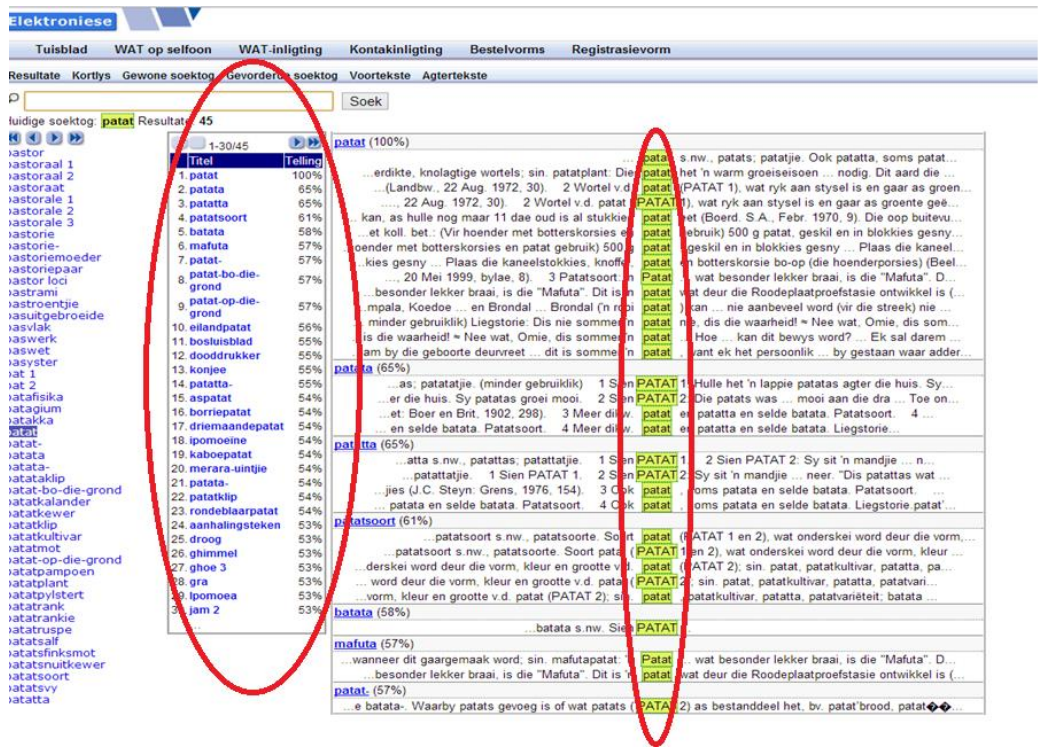

Figure 1.2: The hit-list and shortlist

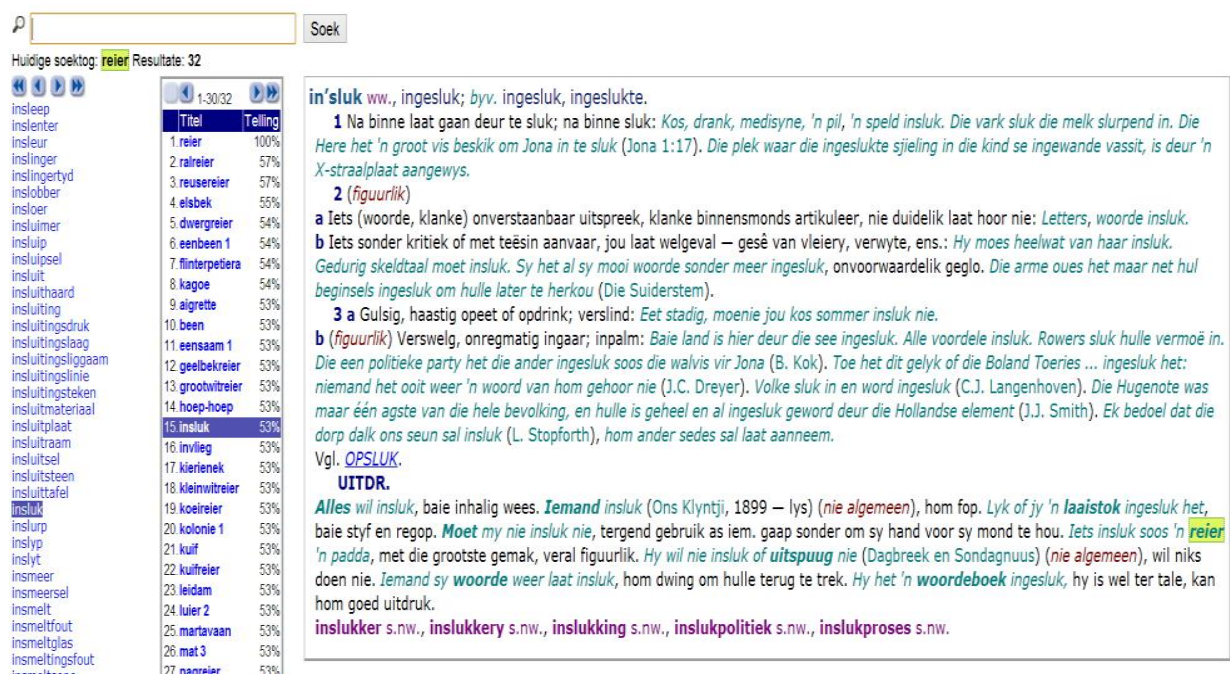

Figure 1.3: A basic search and result 
The problem is that the hit-list and shortlist don't really offer the user much lexicographic guidance and serves no real functional purpose seeing that a user still has to go into that article to find what he/she is looking for. Consequently, it is unclear why the user is presented with these lists. It would be more sensible to offer manipulable data so that the user can individualise his/her WAT experience. As figure 1.3 shows, the only data that is otherwise clickable in the article is when a cross-reference is given. Online dictionaries should be interactive environments where the user can select the exact data he/she is looking for. Not being able to select the functions, data-types or usage-situations, negatively affect the user's ability to use the dictionary effectively. A user must also be allowed to create his/her own changeable profile that allows for different search options depending on the type of user. For example, an advanced user (semi-expert) in law may not need text production information about a certain legal term or phrase, but just wants to check a single meaning to make sure he/she is correct in using the word/phrase.

Upon further inspection of the outer-texts, it seems that user guidance as a whole needs to be addressed in this version. The user is confronted with outertexts that are not linked to the functions of the dictionary they are using. The online WAT's outer-texts give users the same information and usage-guide found with the CD-ROM version (a version that runs on Folio Views and has different search routes). Figure 1.4.1 and 1.4.2 illustrates this incongruity. This is of no help to any user that uses the online or mobile version as there are functions, processes and search routes that are not applicable to the online version. Furthermore, a lot of irrelevant information is presented. It is understandable that the dictionary contributors should get credit, but the layout of the guidance text places this ahead of crucial usage information. An online user wants a simple and quick guide to understanding and using the dictionary. The online WAT fails in this regard. It is imperative that further research be done on the online WAT, as this can permeate into the mobile version and into other South African online dictionaries. The above-mentioned critiques are some of the areas that, once improved, can be applied to the mobile version to enhance its functionality too.

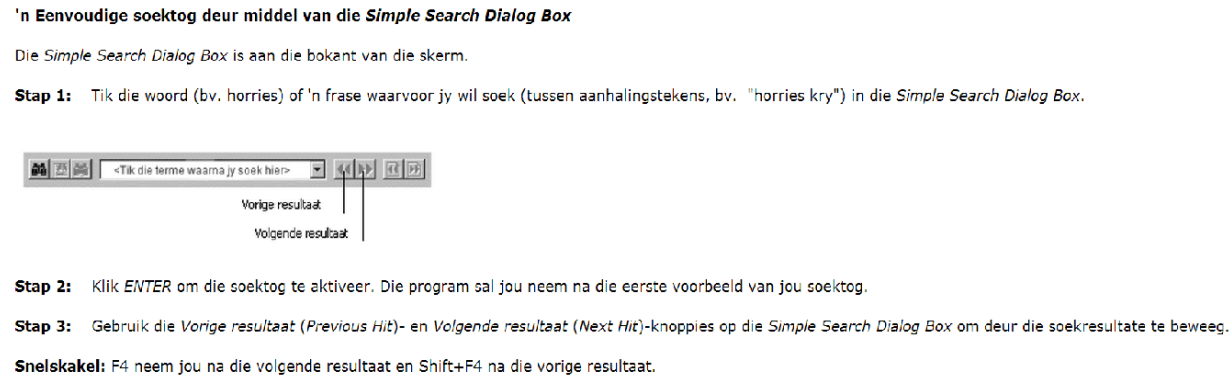

Figure 1.4.1: The CD-ROM versions user guidance given in the online version 


\section{Die Advanced Query Dialog Box}

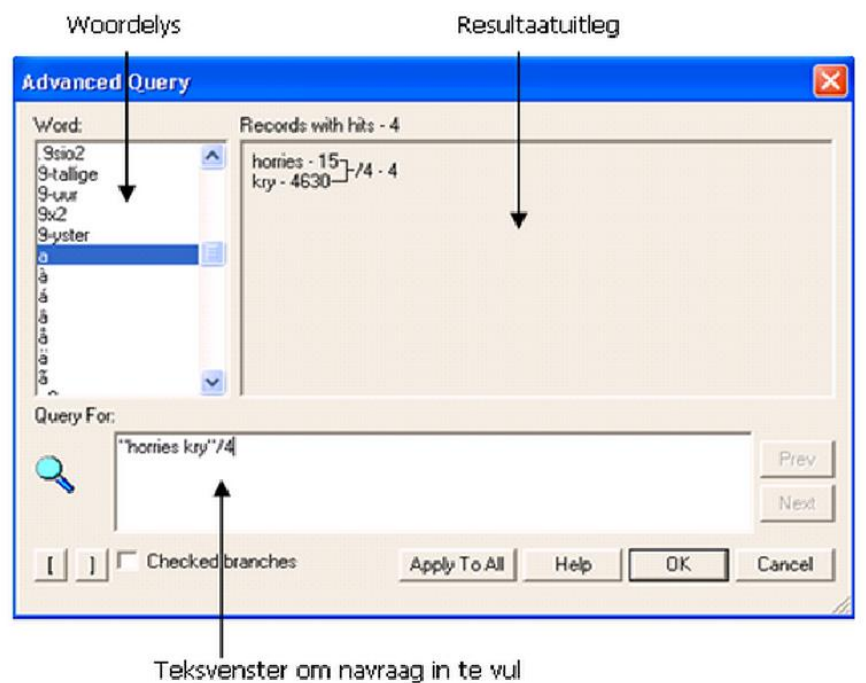

Figure 1.4.2: The advanced query dialog box function. Only available in the CD-ROM version but presented in the outer-text of the online version

\subsection{The mobile WAT}

The mobile version also suffers from a lack of functionality and effective use of available technological attributes. As with the online version, this version is also a digital copy of its printed counterpart. Fundamentally, it is almost a carbon copy of the online WAT. This means it has many of the same problems as well as a few added obstacles. Figure 2 shows the mobile home screen:

\section{WAT-Selfoon Tuisblad}

\section{Resultate}

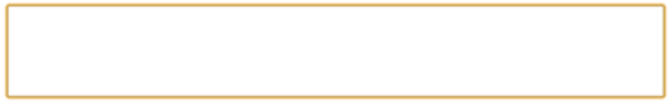

\section{Soek}

\section{Alle Regte Voorbehou}

Figure 2: The mobile WAT

It is clear from Figure 2 that this version offers even less help to its users than 
the online one. This very basic homepage is all that a user is confronted with. Furthermore, this version's search function is very limited. Only single word items can be searched for and no advanced searches can be undertaken whatsoever (Botha 2013). No outer-texts, no links and no help or any other options are given. Even if the user is an advanced user, no dictionary should assume that its users do not need usage guidance. It seems that this version leaves the user to fend for him/herself when navigating or using the dictionary. At first glance, it seems this version is thus not very user-friendly.

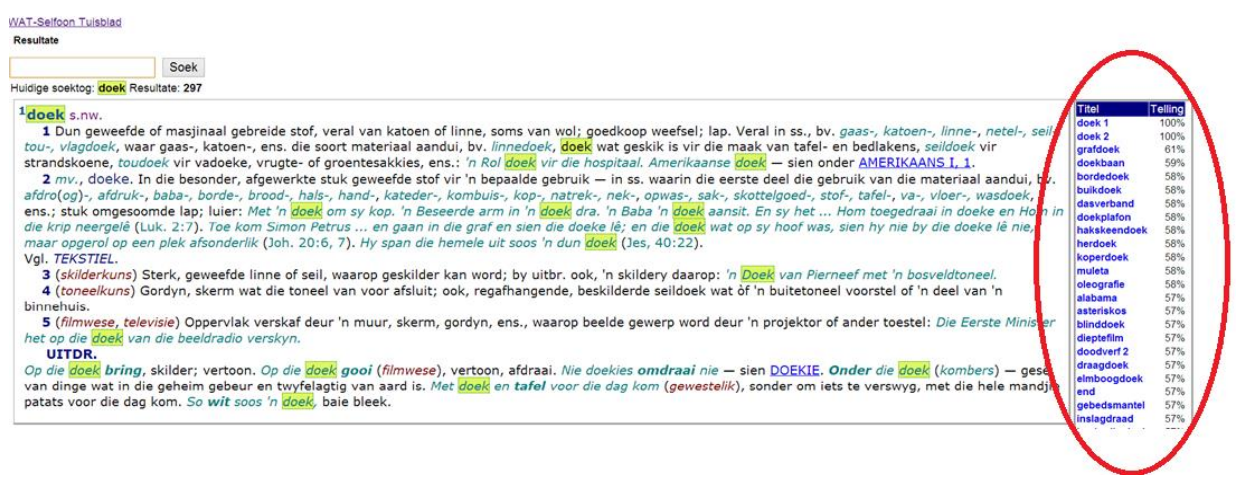

Figure 2.1: A basic search done on the mobile WAT

When a basic search is done, as figure 2.1 shows, the dictionary delivers the results in the same manner as the online version. This is problematic. Again, it must be stated that using the same model as the printed version for an electronic environment, is not sustainable or practicable. For example, figure 2.1 shows the ineffective hit-list, the same layout as the online version and a very static digital environment. The developers also failed to realise that a cellphone has certain limitations with regards to screen layout, but have processing power that allows for innovative ways to display and manipulate data. This means that the layout and structure of the dictionary need to be addressed and the implementation of technological possibilities should be considered. Figure 2.2 echoes this point:

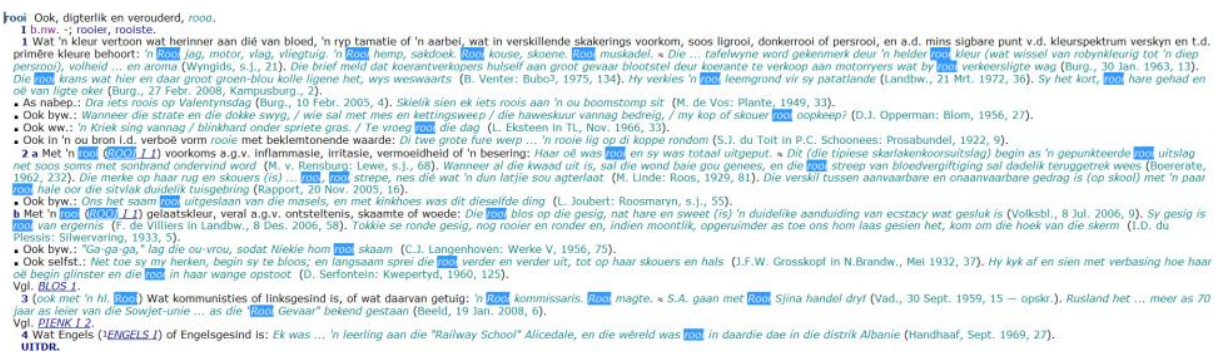

Figure 2.2: Problematic search results 
The search done in figure 2.2 shows the results for the article "rooi" (red). Note that this is not even the full article. It is understandable that due to the WAT's encyclopaedic nature, comprehensive articles are common practice. The problem is not the data but rather the way it is packaged. Therefore an article like "rooi" leads to the following conclusion about the mobile WAT's structure and layout: the user is left to his/her own devices to decipher and sift through a huge mass of information, which in turn frustrate and confuse the user and impairs functionality and usability of the dictionary. Trying to navigate through this dictionary on a cellphone screen is no easy task and by simplifying and adapting the dictionary for mobile use, will greatly improve its functionality. As previously highlighted, the modern dictionary user wants a tool that is simple, effective and adaptable. This means that the WAT must adhere to these needs on a structural and functional level. Having a static layout with an overload of data makes it increasingly difficult to use the dictionary.

As with the online version, not being able to manipulate the data or create a custom profile inhibits the user from satisfying his/her individual needs quickly and easily. The data must be presented in such a way that the lexicographer and user have control over the display and accessibility of data. The mobile WAT does not make use of the technological possibilities on offer to improve these shortcomings. Having the option to create user profiles could be a way to enhance the user's experience, as well as the way data is presented. Thus, innovative access and article structures must be implemented. For example, a manageable home screen with different options and settings that allow users to create an individualised version of the dictionary would vastly improve its structural aspects. This can also be achieved by having tick-boxes for the discrimination of functions or data-types; incorporating a logically set out interface and removing the hit-list and index.

As with the layout, the search functions also need rethinking. Modern smartphones can provide quality products that have lightning quick smart search engines, for example a search function that stores searches, autocompletes searches or aids users by providing suggestions, similar to Google's Did you mean function. As the WAT has such a wide range of users with different language skills, one aspect that also needs addressing is the occurrence of user error in searches. Many users use a dictionary for text production and have trouble spelling. By implementing a spellchecker in the search engine will improve user control and user guidance.

Most mobile phones also have the capacity for multimedia elements. The printed version has some ostensive elements, although they are not used consistently. The mobile and online sphere offers the chance for developers to incorporate different multimedia elements consistently, by creating an interactive dictionary. This in turn would also enhance the user's experience, allow for the knowledge-orientated function of the dictionary to be modernised and improve on the functionality of the dictionary. The use of different multimedia links should thus be taken into consideration. This can be done in the form of 
video clips, ostensive defining and multi-dimensional cross-referencing, i.e. having additional clickable links that either displays a diagram/photo/picture/video or that takes the user to an external site where more information is given. Pop-ups can also be used where either with additional, grammatical or syntactical information is given should the user require it. This would also aid users in extra lexicographic tool situations.

As Bergenholtz and Bothma (2011: 61-62) states: a dictionary is an information tool to be used by a specific set of users. The WAT is a good information tool but lacks accessibility and usability. The e-versions compensate by being more accessible, but not functional. A new brand of techno-savvy user is on the rise and if the WAT wants to make an impact on these users, a mindshift needs to be made. According to Gouws (2013) the current crop of printed WAT users will eventually die out and be replaced by the modern user with a know-how perspective of all things mobile and electronic. Even Botha (2014), the editor of the WAT, states that there is an increase in the sales of electronic versions and that mostly older people buy the printed version. This means that eventually those older users will disappear, which leaves the new generation of users, a generation with different expectations and needs, with a product that cannot satisfy their needs or meet those expectations.

Thus for the e-WAT to be sustainable and marketable as a practical and proper lexicographic tool in the long-term, a division of resources must be allocated. In other words the current versions and future parts should be reworked to be more online or cellphone compatible. Funding is a serious problem and the WAT has struggled with service providers and licensing costs for the past two years (Botha 2014), which has slowed production. This is a problem that can potentially be solved by setting the e-versions as a priority, as it could generate a new market of modern users. This also allows for the updating of older parts and having a dictionary that is continuously updated, which in turn continuously satisfy user needs. The mobile and online version should also be promoted to flagship projects and should not only be seen as part of the printed version's progress.

\section{Recommendations}

This section will provide a few recommendations that stem from the WAT's analysis, which can be applied to mobile dictionaries in general. Lew's (2012: 344) statement is valuable to keep in mind when developing recommendations: "dictionaries should be able to satisfy [user] needs in a short time and with a degree of detail. [T] he data has to be presented in a form that is maximally comprehensible."

Firstly, it must be emphasised that South Africa does not have the infrastructure to support dictionary development like Great Britain, Germany or Japan. We also have a vast array of multicultural users. As Prinsloo (2012) proposes for online dictionaries in South Africa, our future mobile dictionaries 
should also initially be monofunctional. Only when we perfect monofunctional dictionaries and the standard for mobile dictionaries has been set, can we start designing polyfunctional dictionaries. This proposal is especially aimed at new dictionaries or at languages that do not have proper standardised dictionaries.

The effectiveness of any product is usually analysed in conjunction with the products relationship with its users (Heid 2011: 292). This goes for dictionaries too. The differences in user needs will ultimately play a part in the fluctuation of effectiveness. Therefore Heid (2011: 294) proposes some criteria whereby effectiveness is measured. Even though these criteria are for most machine interactions, they have been specifically adapted to suit electronic dictionaries:

- Stability for the task: the dictionary interface should be able to facilitate a range of tasks as set out by the user. An interface should streamline communication between the dictionary and the user.

- Self-descriptiveness: the dictionary interface should be clear and informative, give clear feedback and data should be visible and recognisable.

- Controllability: user interaction is crucial. Users should have control over their dictionary interface.

- Conformity with user expectations: the dictionary should behave in a way the user expects, i.e. should behave as a dictionary should and not be unfamiliar to users.

- Error tolerance: user error must be expected and processes must be in place to guide users when this occurs. Reversals should be done indeed necessary.

- Suitability for individualisation: customisation or individualisation should be allowed. A user must make the dictionary his/her own.

- Suitability for learning: the dictionary should be quick and easy to master, with adequate guidelines and mediating functions in place.

It is very important that a dictionary developer takes these criteria into consideration when designing a mobile or online product, as this has a significant effect on the usability and marketability of the dictionary.

Heid's criteria fits well within the framework that Fuertes-Olivera and Niño-Amo (2011: 172-173) drew up for online dictionary design. It is also possible to adapt some of these guidelines for mobile dictionaries. As with the Heid's criteria, my supplementary ideas have been amalgamated with FuertesOlivera and Niño-Amo's guidelines:

- Smart Searches: A mobile dictionary should be able to do smart searches, similar to Google's search engine. Different search routes or functions should be available. Different articles/lemmas/data-types should be searchable in different ways. For example being able to highlight words in a defi- 
nition and being able to search for said text.

- Interactivity: Users must feel part of the dictionary. The dictionary should be a familiar environment that highlights user interaction by means of various personalisation options, clickable links, user input and/or guidance. They should also not be alienated by confusing data-types/styles / presentations. They should also have the freedom to give their input to enhance the dictionary.

- Layout: User-friendliness is essential. The dictionary must be pleasant to look at, incorporate different technological measures to ensure that it is fast, simple, aesthetically pleasing and logically set out. Everything should be clearly labelled and must feel inviting to use. Bothma's (2011: 83) ideas for online dictionaries are also valid here: mobile dictionaries must be designed in such a way that users can navigate effortlessly through the macro- or microstructure. They must not be bombarded with options, details or links that crowd the screen or that cannot close/be minimized. There should be a main menu that is easy to understand and follow, and which can be returned to at any time.

- Multimedia possibilities: Multimedia should be incorporated, especially as a variation on data-types or as supplement to existing articles. The use of ostensive defining, video clips or even sound clips can be utilised to present users with extra information on articles if needed. Sound clips can be very handy for pronunciation purposes, as users can at least hear the standard variety of pronunciation of a word.

- Familiarity: The virtual environment should not be too different from a printed dictionary, i.e. the dictionary should still be recognisable as a dictionary. Articles can be given in innovative ways but should still meet the average user's expectations. Adverts and other distracting elements should be avoided, as this limits the screen space of the dictionary and presents an overload of data.

- Extra software functions: Functions that are linked to the mobile phone, such as copy-and-paste, highlighting text, minimizing or signing in/out, should be taken into consideration as they offer extra functionality and usability to the dictionary.

- Updating: Updates and corrections are needed, especially if users have asked for them. Updates can be expensive or time-consuming, but they are a necessary part of improving dictionaries. Updates should be done regularly (once a week at least), but users should be able to choose whether they want the update or not. Apps that continuously update are very irritating and consume precious network data, which is problematic for users that only have a set amount of data each month. The dictionary should still be functional even if it is not updated or it should be downloadable with an offline-mode. 
- Search results: Firstly, search results must be readable and fit to the size of the phone's screen. Only relevant information should be presented. The information/data should be logically set out. As mentioned, advanced searches should be a given, but they should be manipulable and be usable in search results too, for example users should be able to dictate what criteria they want their results to be sorted by (theme, word length, collocations, etc.).

The analysis of the WAT emphasises the lack of customisation that e-dictionaries seem to have. One area that can improve this shortcoming is to introduce user profiles. As Bothma (2011: 84) states: "This can help to reduce information overload and provide the user with customized information tailored to his/her specific needs in a specific situation." This implies that users will find relevant data quicker if they have a profile set to their specifications. Thus, another recommendation can be added to the above-mentioned:

- User profiling: Users should be able to sign into a dictionary and create a custom profile that can be adapted to their needs. This in turn will emphasise the adaptability of mobile dictionaries as practical tools. The user profile must indicate: the user type (expert, semi-expert or layman — this can refer to dictionary usage knowledge or language proficiency) and their function or data-type preference.

Another area that needs to be addressed is that of guidance in text production, especially in translation situations. Prinsloo, Heid, Bothma en Faaß (2012: 292) have already looked at this in online dictionaries, but it pertains to mobile dictionaries too. This can be very useful for creating monofunctional translation dictionaries, for second or foreign language speakers. Giving user guidance in the form of pop-ups would work well. These pop-ups could contain grammatical, syntactical or morphological information about the source language (Prinsloo et al. 2012: 296). This is not the only method, as innovative markers could also be user. These markers could be in different colours and shapes, and would be used to warn users about the use of loaded or confusing words, homonyms, homophones, etc. For example an interactive red flag that when clicked gives a concise explanation and an example to illustrate the usage situation.

These guidelines or recommendations are just a few key aspects that need to be addressed if mobile dictionaries are to improve. One of the biggest problems that currently exist in South African lexicography is the use of printed dictionary structures for online and mobile user. Dziemianko (2012: 321) makes a good point when she says that online and mobile dictionaries do not have to have rigid structures like printed dictionaries. The fact that "layered presentations" can be used and that dynamic data-presentation is possible, as well as the fact that there are no real limits to storage space, should give these mediums authority in the modern era (Dziemianko 2012: 321). The printed diction- 
ary sphere should however not be ignored as it too can benefit from the improvement of online or mobile dictionaries.

\section{Conclusion}

This article looked at the e-WAT as a guinea pig for the application of some lexicographic theories as a starting-point to improve Afrikaans and other cellphone dictionaries. Many of these recommendations are not applicable in the short-term, but need to be addressed if the WAT wants to survive in a very fast changing lexicographic landscape. The current e-versions are not as effective as they can be. There are still too many shortcomings for it to be a sustainable and practically usable electronic lexicographic tool. The WAT is a very good dictionary and they do an outstanding job in setting the standard for lexicographic practice in South Africa, but the fact remains that the shift towards electronic mediums will greatly affect them too in the not-too-distant future.

Creating a tool that encompasses the technological possibilities available and that satisfies the new generation of users' needs, will bode well for South African lexicography and might even attract a completely new group of users to the WAT. This is the perfect opportunity to fill the void that currently exists in the Afrikaans cellphone market.

A range of recommendations is made that can be incorporated into mobile dictionaries. It is obvious that not all of these recommendations are applicable on every dictionary or on one single dictionary, but a combination of these guidelines should be taken to heart when designing mobile lexicographic tools for the future.

In conclusion, a lot of research is still needed on mobile and online dictionaries, and as with any scientific process, a period of trial and error lies ahead. This study shows that the mobile version of the WAT is not yet a truly functional electronic tool, but by applying some of the recommendations made for improvement, it will become the basis for a whole range of other mobile dictionaries in South Africa or Africa. There are, however, also other problems that South African lexicography is faced with. Many socio-economic factors impede the implementation of sustainable reference sources in South Africa. Out multicultural population can also cause some obstacles for the development of online or mobile dictionaries. More research needs to be done in this regard.

\section{References}

Anderson, B. and S. Nielsen. 2009. Ten Key Issues in Lexicography for the Future. Bergenholtz, H., S. Nielsen and S. Tarp (Eds.). 2009: 355-363.

Bergenholtz, H., S. Nielsen and S. Tarp (Eds.). 2009. Lexicography at a Crossroads: Dictionaries and Encyclopaedias Today, Lexicographical Tools Tomorrow. Linguistic Insights. Studies in Language and Communication 90. Bern: Peter Lang. 
Bergenholtz, H. and T.J.D. Bothma. 2011. Needs-adapted Data Presentation in e-Information Tools. Lexikos 21: 53-77.

Botha, W.F. (wfb@sun.ac.za), 15 August 2013. Re: Selfoonwoordeboek. E-mail to A. du Plessis (15612538@sun.ac.za).

Botha, W.F. 2014. Personal Interview, 27 March 2014, Stellenbosch.

Bothma, T.J.D. 2011. Filtering and Adapting Data and Information in an Online Environment in Response to User Needs. Fuertes-Olivera, P.A. and H. Bergenholtz (Eds.). 2011: 71-102.

Buys, A.J. and L.M.M. Malebo. 2004. Managing Rapid Diffusion: The Case of Cellular Communications in South Africa. SA Journal of Industrial Engineering 15(2): 67-78.

De Schryver, G.-M. 2003. Lexicographers' Dreams in the Electronic-Dictionary Age. International Journal of Lexicography 16(2): 143-199.

Dziemianko, A. 2012. On the Use(fulness) of Paper and Electronic Dictionaries. Granger, S. and M. Paquot (Eds.). 2012: 319-337.

Elektroniese WAT. 2013. [Online] http://www.woordeboek.co.za.

Fuertes-Olivera, P.A. 2009. The Function Theory of Lexicography and Electronic Dictionaries: WIKTIONARY as a Prototype of Collective Free Multiple-language Internet Dictionary. Bergenholtz, H., S. Nielsen and S. Tarp (Eds.). 2009: 99-131.

Fuertes-Olivera, P.A. and H. Bergenholtz (Eds.). 2011. e-Lexicography: The Internet, Digital Initiatives and Lexicography. London/New York: Continuum International.

Fuertes-Olivera, P.A. and M. Niño-Amo. 2011. Internet Dictionaries for Communicative and Cognitive Functions: El Diccionario Inglés Español de Contabilidad. Fuertes-Olivera, P.A. and H. Bergenholtz (Eds.). 2011: 168-186.

Google. 2013. Our Mobile Planet. [Online] http://think.withgoogle.com/mobileplanet/en/.

Gouws, R.H. 2011. Learning, Unlearning and Innovation in the Planning of Electronic Dictionaries. Fuertes-Olivera, P.A. and H. Bergenholtz (Eds.). 2011: 168-186.

Gouws, R.H. 2013. Die geskiedenis van die WAT. Class Lecture (Afrikaanse Leksikografieteorie 771). Stellenbosch: Stellenbosch University.

Granger, S. and M. Paquot (Eds.). 2012. Electronic Lexicography. Oxford: Oxford University Press.

Heid, U. 2011. Electronic Dictionaries as Tools: Toward an Assessment of Usability. Fuertes-Olivera, P.A. and H. Bergenholtz (Eds.). 2011: 287-304.

Lew, R. 2012. How Can We Make Electronic dictionaries More Effective? Granger, S. and M. Paquot (Eds.). 2012: 343-361.

Oshima, J. 2013. The Digital Dictionary: Classroom Use in Japan. Paper read at the 8th International Conference of the Asian Association for Lexicography (ASIALEX 2013), 20-22 August 2013, Bali, Indonesia.

Peyper, L. 2013. Mobile Phone Usage in SA.. Finweek [Online] http://finweek.com/2013/01/22/ mobile-phone-usage-in-sa/. [Accessed: 24 September 2013].

Prinsloo, D.J. 2012. Electronic Lexicography for Lesser-resourced Languages: The South African Context. Granger, S. and M. Paquot (Eds.): 119-144.

Prinsloo, D.J., U. Heid, T. Bothma and G. Faaß. 2012. Devices for Information Presentation in Electronic Dictionaries. Lexikos 22: 290-320.

Selfoon-WAT. 2013. [Online] http://sel.woordeboek.co.za.

Smith, W. 2013. Pharos Dictionaries. Personal Interview, 26 August, Cape Town.

Statistics South Africa. 2014. General Household Survey 2013. Pretoria: Statistics South Africa. 
http://lexikos.journals.ac.za

Tarp, S. 2000. Theoretical Challenges to Practical Specialised Lexicography. Lexikos 10: 189-208.

Tarp, S. 2009. Beyond Lexicography: New Visions and Challenges in the Information Age. Bergenholtz, H., S. Nielsen and S. Tarp (Eds.). 2009: 17-31.

Tarp, S. 2012. Theoretical Challenges in the Transition from Lexicographical p-Works to e-Tools. Granger, S. and M. Paquot (Eds.). 2012: 107-118

Tono, Y. 2009. Pocket Electronic Dictionaries in Japan: User Perspectives. Bergenholtz, H., S. Nielsen and S. Tarp (Eds.). 2009: 33-67.

Winestock, C. and Y. Jeong. 2014. An Analysis of the Smartphone Dictionary App Market. Tono, Y. (Ed.). 2014. Lexicography Journal of ASIALEX 1(1): 109-119. 